\title{
RYZYKO WYSTĄPIENIA KONDENSACJI PARY WODNEJ W ZEWNECTRZNYCH PRZEGRODACH POZIOMYCH
}

\begin{abstract}
Celem pracy jest sprawdzenie wystąpienia kondensacji pary wodnej w stropodachu zielonym, będącym pokryciem budynku mieszkalnego wielorodzinnego, dla którego określono trzecią klasę obciążenia wilgocią - budynki o niskim stopniu zaludnienia. Stropodach cechuje się układem warstw, w których zmiennej grubości termoizolacja jest układana ze spadkiem w kierunku koryta odwadniającego. Minimalna grubość termoizolacji to $25 \mathrm{~cm}$, a maksymalna będąca wynikiem obliczeń, to około $31,5 \mathrm{~cm}$. Wyznaczając grubość termoizolacji w poszczególnych miejscach stropodachu posłużono się krokiem wynoszącym $50 \mathrm{~cm}$ tworząc siatkę punktów opisujących poszczególne przekroje stropu. Sprawdzenia dokonano w oparciu o definicję współczynnika temperaturowego. Średnie miesięczne wartości temperatury na zewnątrz budynku uzyskano w oparciu o bazę danych Instytutu Meteorologii i Gospodarki Wodnej za rok 2015. Na początku obliczono miesięczne zewnętrzne ciśnienie pary wodnej. Następnie wyznaczono zewnętrzne ciśnienie pary wodnej oraz nadwyżkę wewnętrznego ciśnienia pary wodnej w sposób odpowiedni dla trzeciej klasy obciążenia wilgocią. Kolejno obliczenie wewnętrznego ciśnienia pary wodnej i minimalnego dopuszczalnego ciśnienia pary nasyconej doprowadziło do obliczenia minimalnej dopuszczalnej temperatury na powierzchni przegrody. Dla założonego układu warstw dachowych nie występuje ryzyko wystąpienia kondensacji pary wodnej, a co za tym idzie uniknięto wystąpienia pleśni i grzybów wewnątrz budynku. Ma to bardzo duże znaczenie nie tylko estetyczne, ale szczególnie ważne wobec osób cierpiących na alergię. Uniknięcie wszelkiego rodzaju grzybów i pleśnie w pomieszczeniu pomaga stworzyć właściwy mikroklimat.
\end{abstract}

Słowa kluczowe: współczynnik temperaturowy, dach zielony, skraplanie pary wodnej, współczynnik temperaturowy

\section{Wprowadzenie}

Dachami zielonymi określa się wszystkie miejsca na konstrukcjach budowli, które odtwarzając naturalne warunki gruntowe pozwalają na trwałe, ściśle związane z konstrukcją budynku tworzenie terenów biologicznie czynnych. Zieleń na dachu to sposób na odtworzenie zabranej naturze, pod zabudowę i infra-

\footnotetext{
${ }^{1}$ Daniel Gawryś, Wojskowa Akademia Techniczna, Zakład Budownictwa Ogólnego, ul. Kaliskiego 2, d.gawrys20@gmail.com
} 
strukturę komunikacyjną, powierzchni terenu biologicznie czynnej. Parametrem służącym do oceny niebezpieczeństwa tworzenia się pleśni na powierzchni przegród budowlanych jest współczynnik temperaturowy. Jest to różnica pomiędzy temperaturą powierzchni i temperaturą powietrza na zewnątrz podzielona przez różnicę temperatury powietrza wewnętrznego i zewnętrznego. Wartość współczynnika temperaturowego jest wartością względną i ma tę zaletę, że zależy wyłącznie od warunków przejmowania ciepła na powierzchni przegrody, a nie od założonych temperatur wewnątrz i na zewnątrz budynku. [1]

\subsection{Podział dachów zielonych i ich funkcje}

Podstawowym kryterium podziału jest sposób rozwoju roślinności - dachy ekstensywne i intensywne. O dachach ekstensywnych mówimy wtedy, kiedy warstwa medium wzrostowego dla roślin jest nie większa niż kilkanaście centymetrów. Takie rozwiązanie świetnie się sprawdza przy stosowaniu na wcześniej wybudowanych konstrukcjach, ponieważ ich ciężary z reguły nie przekraczają $200 \mathrm{~kg} / \mathrm{m}^{2}$. Dachy ekstensywne nie są przeznaczone do częstych odwiedzin, a wręcz dobrze jest je ograniczyć do minimum wymaganego przez konserwację. Dachy intensywne to dachy zielone, które cechuje gruba warstwa medium roślinnego, mogącego sięgać wysokości do jednego metra. Niestety wraz ze wzrostem grubości konieczne jest umocnienie konstrukcji. Masa tego typu dachów wynosi od $1000-1200 \mathrm{~kg} / \mathrm{m}^{2}$. Kolejnym podział dotyczy stropodachów niosących cały układ dachu zielonego, tu wyróżniamy tradycyjny stropodach pełny i stropodach odwrócony. W stropodachu pełnym warstwa hydroizolacyjna (najczęściej papa lub membrana) układana jest bezpośrednio na termoizolacji. Natomiast $\mathrm{w}$ przypadku stropodachu odwróconego termoizolacja znajduje się na warstwie hydroizolacyjnej. Jest to rozwiązanie wprowadzone na rynek dopiero wtedy, gdy dostępne stały się materiały odporne na pełne zawilgocenie - np. polistyren ekstrudowany XPS. [1] W tym rozwiązaniu wilgoć, która nie została odprowadzona poprzez system drenażowy przesiąka przez warstwę izolacji termicznej i jest odprowadzana do powierzchni warstwy hydroizolacyjnej. Ostatni podział dotyczy nachylenia i tu wyróżniamy:

- stropodach płaski - maksymalny kąt nachylenia 10 stopni celem odprowadzenia wody opadowej,

- skośny - spadek w granicach 10-25 stopni, który nadal nie wymaga dodatkowych zabezpieczeń darniny i roślin przez osunięciem,

- stromy - nachylenie przekraczające 25 stopni, w tym przypadku poszycie wymaga dodatkowych prowadnic lub kompozytów zapobiegających niekontrolowanemu zsunięciu.

Zasadniczo dachy zielone są tworzone jako uzupełnienie powierzchni biologicznie czynnych, jednak zalety ich budowy obejmują znacznie szerszy zakres. Redukują ilość odpływających wód opadowych, akumulują ciepło zimą i chłodzą budynek latem. Mają też pozytywny wpływ na trwałość pokrycia i kon- 
strukcji dachu. Poprawiają mikroklimat miejski, redukując efekt miejskiej wyspy ciepła. Do podstawowych funkcji należą:

- tworzenie powierzchni biologicznie czynnej,

- ochronę pokrycia dachu,

- redukcję odpływających wód opadowych,

- dodatkową izolację termiczną,

- zmniejszenie efektu "miejskich wysp ciepła,

- podwyższenie izolacyjności akustycznej,

- podwyższenie walorów estetycznych.

\subsection{Klasy wilgotności pomieszczeń}

W modelu wentylacji grawitacyjnej obsługującej większość budynków mieszkalnych i usługowych, wilgotność wewnętrzna pomieszczenia w zależności określonej zarówno do funkcji pomieszczenia jak i warunków klimatu zewnętrznego $[2,3]$. Opierając się na badaniach z Europy Zachodniej zaproponowano normowy podział budynków w ramach pięciu klas obciążenia wilgocią wewnętrzną (rys. 1):

- klasa 1 - pomieszczenia magazynowe, zakłady z suchą produkcją,

- klasa 2 - biura, sklepy,

- klasa 3 - mieszkania mało zagęszczone (z małą ilością mieszkańców),

- klasa 4 - mieszkania zagęszczone, hale sportowe, kuchnie, stołówki, pomieszczenia w budynkach ogrzewanych grzejnikami gazowymi bez przewodów spalinowych,

- klasa 5 - pomieszczenia w budynkach specjalnych, np. pralnie, browary, baseny kąpielowe.

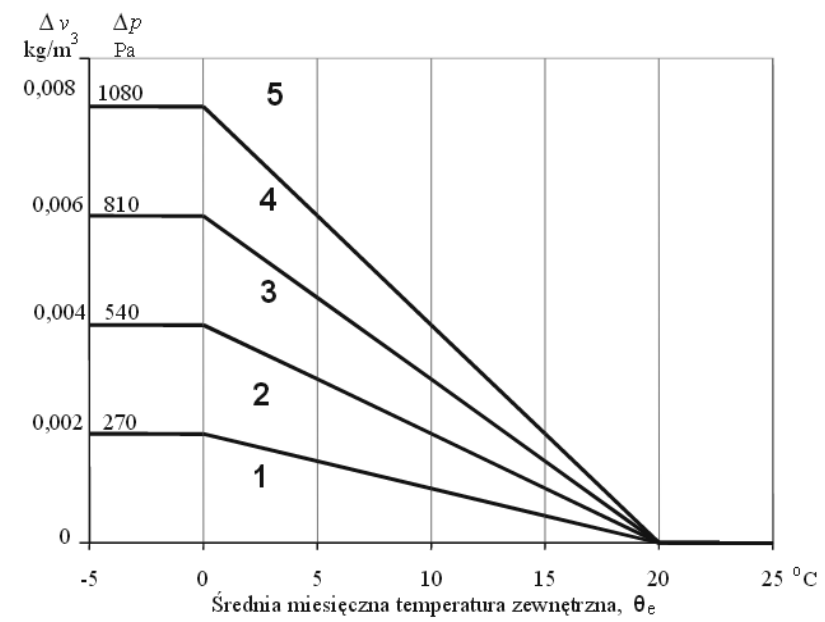

Rys. 1. Klasy wilgotności pomieszczeń

Fig. 1. Class humidity rooms 


\section{Opis procedury badawczej}

\subsection{Opis analizowanego przykładu}

Do analizy został przyjęty stropodach zielony będący przekryciem budynku zamieszkania zbiorowego w Warszawie o następującym układzie warstw - tabela 1. Układ warstw dachowych (w kierunku od góry do dołu).

Tabela 1. Układ warstw dachowych

Table 1. Layout of the roof

\begin{tabular}{|l|c|c|c|}
\hline & $\begin{array}{c}\lambda \\
{[\mathbf{W} /(\mathbf{m} \cdot \mathbf{K})]}\end{array}$ & $\mathbf{D}[\mathbf{m}]$ & $\begin{array}{c}\mathbf{R} \\
{\left[\mathbf{m}^{2} \mathbf{K} / \mathbf{W}\right]}\end{array}$ \\
\hline Substrat glebowy & 0,9 & 0,3 & 0,333 \\
\hline Keramzyt - warstwa drenażowa & 0,29 & 0,05 & 0,172 \\
\hline $\begin{array}{l}\text { Papa termozgrzewalna na osnowie poliestrowej } \\
\text { układana w dwóch warstwach (warstwa podkła- } \\
\text { dowa + warstwa wierzchnia) }\end{array}$ & 0,174 & 0,007 & 0,040 \\
\hline $\begin{array}{l}\text { Podkład betonowy zbrojony włóknami Fibre- } \\
\text { mash gr. 6 cm }\end{array}$ & 1,05 & 0,06 & 0,057 \\
\hline $\begin{array}{l}\text { Styropian Super EPS 200 035 gr. Min. 25 cm } \\
\text { w spadku }\end{array}$ & 0,033 & 0,25 & 7,576 \\
\hline Strop żelbetowy grubość 25 cm & 1,7 & 0,25 & 0,118 \\
\hline Tynk gipsowo-piaskowy gr. 1,5 cm & 0,82 & 0,015 & 0,018 \\
\hline
\end{tabular}

Budynek znajduje się w 3 klasie obciążenia wilgocią z uwagi na stopień zaludnienia. Poniżej układ spadków w termoizolacji mający wpływ na wartość współczynnika przenikania ciepła dla każdego punktu w stropodachu z krokiem siatki wynoszącym $50 \mathrm{~cm}$. Najmniejsza grubość termoizolacji znajduje się w obrębie koryta odwadniającego i wynosi $25 \mathrm{~cm}$. Podyktowane jest to przede wszystkim najmniejszą wartością współczynnika przenikania ciepła jakie powinny mieć stropodachy nad lokalami mieszkalnymi. Najwyższa zaś grubość wynosi około $31.5 \mathrm{~cm}$ i jest to obszar w miejscach styku połaci dachowej ze ścianą attykową (rys. 2). 


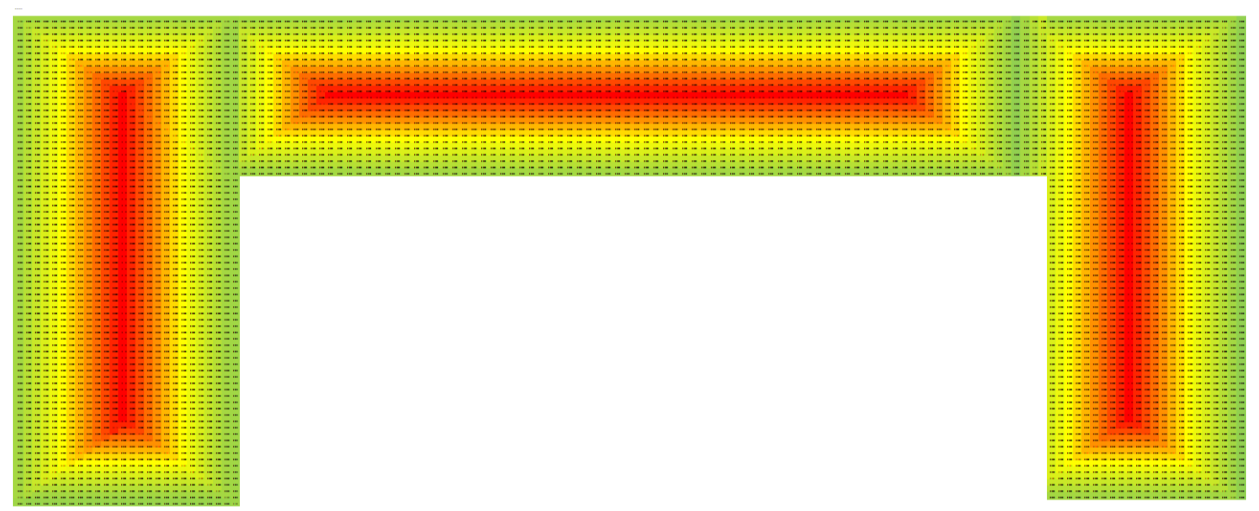

Rys. 2. Układ spadków w termoizolacji - pola czerwone oznaczają najmniejszą grubość - $25 \mathrm{~cm}$, zaś zielone najwyższą - $31,5 \mathrm{~cm}$

Fig. 2. The system decreases the insulation - red boxes indicate the minimum thickness $-25 \mathrm{~cm}$, while the green highest $-31,5 \mathrm{~cm}$

\subsection{Opis postępowania}

- Obliczenie miesięcznego zewnętrznego ciśnienia pary wodnej $\mathrm{p}_{\mathrm{sat}, \mathrm{e}}$.

$$
p_{\text {sat }, e}=610 \cdot e^{\frac{17,269 \cdot \theta_{e}}{237,5+\theta_{e}}} d l a \theta_{e} \geq 0^{\circ} \mathrm{C}
$$

gdzie: $\theta_{\mathrm{e}}$ - temperatura zewnętrzna $\left[{ }^{\circ} \mathrm{C}\right]$.

$$
p_{\text {sat }, e}=610 \cdot e^{\frac{21,875 \cdot \theta_{e}}{265,5+\theta_{e}}} d l a \theta_{e}<0^{\circ} \mathrm{C}
$$

gdzie: $\theta_{\mathrm{e}}$ - temperatura zewnętrzna $\left[{ }^{\circ} \mathrm{C}\right]$.

- Obliczenie zewnętrznego ciśnienia pary wodnej $\mathrm{p}_{\mathrm{e}}$.

$$
p_{e}=p_{s a t, e} \cdot \varphi_{e}
$$

gdzie: $\varphi_{e}$ - wilgotność zewnętrzna [\%].

- Obliczenie nadwyżki wewnętrznego ciśnienia pary wodnej.

Nadwyżkę wewnętrznego ciśnienia pary wodnej można obliczyć według poniższych wzorów w zależności klasy wilgotności pomieszczenia dla dodatnich średnich temperatur powietrza (tab. 2). 
Tabela 2. Nadwyżka wewnętrznego ciśnienia pary wodnej dla temperatur dodatnich

Table 2. The surplus of the internal steam pressure for positive temperatures

\begin{tabular}{|c|c|}
\hline $\begin{array}{c}\text { Nadwyżka wewnętrznego ciśnienia } \Delta \boldsymbol{p} \\
\text { dla } \boldsymbol{\theta}_{\boldsymbol{e}}>0[\mathbf{P a}]\end{array}$ & Klasa wilgotności pomieszczenia \\
\hline$\Delta p=-13,5 \cdot \theta_{e}+270$ & 1 \\
\hline$\Delta p=-27 \cdot \theta_{e}+540$ & 2 \\
\hline$\Delta \boldsymbol{p}=-\mathbf{4 0 , 5} \cdot \boldsymbol{\theta}_{\boldsymbol{e}}+\mathbf{8 1 0}$ & $\mathbf{3}$ \\
\hline$\Delta p=-54 \cdot \theta_{e}+1080$ & 4 \\
\hline
\end{tabular}

Dla ujemnych średnich miesięcznych temperatur nadwyżki wewnętrznego ciśnienia pary wodnej należy uwzględnić jak w tab. 3:

Tabela 3. Nadwyżka wewnętrznego ciśnienia pary wodnej dla temperatur ujemnych

Table 3. The surplus of the internal pressure of the water vapor freezing temperatures

\begin{tabular}{|c|c|}
\hline Klasa wilgotności pomieszczenia & $\begin{array}{c}\text { Nadwyżka wewnętrznego ciśnienia } \Delta \boldsymbol{p} \\
\text { dla } \boldsymbol{\theta}_{\boldsymbol{e}}<0[\mathbf{P a}]\end{array}$ \\
\hline 1 & $\leq 270$ \\
\hline 2 & $>270 \leq 540$ \\
\hline $\mathbf{3}$ & $>\mathbf{5 4 0} \leq \mathbf{8 1 0}$ \\
\hline 4 & $>810 \leq 1080$ \\
\hline 5 & $>1080$ \\
\hline
\end{tabular}

- Obliczenie wewnętrznego ciśnienia pary wodnej.

$$
p_{i}=p_{e}+\Delta p
$$

gdzie: $p_{e}$ - zewnętrzne ciśnienie pary wodnej [Pa],

$\Delta p$ - nadwyżka wewnętrznego ciśnienia pary wodnej [Pa].

- Obliczenie minimalnego dopuszczalnego ciśnienia pary nasyconej $\mathrm{p}_{\mathrm{sat}}\left(\theta_{\mathrm{si}}\right)$.

$$
p_{\text {sat }}\left(\theta_{\text {si }}\right)=\frac{p_{i}}{0,8}
$$

gdzie: $p_{i}$ - zewnętrzne ciśnienie pary wodnej [Pa].

- Obliczenie minimalnej dopuszczalnej temperatury powierzchni przegrody $\theta_{\text {si,min }}$.

Dopuszczalną temperaturę powierzchni przegrody należy obliczyć uwzględniając wartość minimalnego dopuszczalnego ciśnienia pary nasyconej:

$$
\theta_{\text {si,min }}=\frac{237,3 \cdot \log _{e}\left(\frac{p_{s a t}}{660,5}\right)}{17,269-\log _{e}\left(\frac{p_{s a t}}{610,5}\right)} \text { dla } p_{\text {sat }} \geq 610,5 \mathrm{~Pa}
$$

gdzie: $\mathrm{p}_{\text {sat }}$ - minimalne dopuszczalne ciśnienie pary nasyconej [Pa]. 


$$
\theta_{\text {si,min }}=\frac{265,5 \cdot \log _{e}\left(\frac{p_{\text {sat }}}{610,5}\right)}{21,875-\log _{e}\left(\frac{p_{s a t}}{610,5}\right)} \text { dla } p_{\text {sat }}<610,5 \mathrm{~Pa}
$$

gdzie: $\mathrm{p}_{\text {sat }}$ - minimalne dopuszczalne ciśnienie pary nasyconej [Pa].

- Ustalenie temperatury wewnętrznej $\theta_{\mathrm{i}}$.

Według 3 klasy wilgotności analizowany budynek należy do budynków mieszkalnych o niskim stopniu zaludnienia. To znaczy, że mamy do czynienia prawdopodobnie $\mathrm{z}$ domem jednorodzinnym. Temperatura wewnętrzna $\mathrm{w}$ domu wielorodzinnym powinna wynosić średnio 20 stopni Celsjusza i tę wartość przyjmiemy do obliczeń. [2]

- Obliczenie współczynnika temperatury na powierzchni wewnętrznej $\mathrm{f}_{\text {Rsi,max }}$.

$$
f_{R s i, \max }=\frac{\theta_{s i}-\theta_{e}}{\theta_{i}-\theta_{e}}
$$

gdzie: $\theta_{s i}$ - temperatura powierzchni wewnętrznej przegrody [ $\left.{ }^{\circ} \mathrm{C}\right]$,

$\theta_{i}$ - temperatura wewnątrz pomieszczenia $\left[{ }^{\circ} \mathrm{C}\right]$,

$\theta_{e}$ - temperatura na zewnątrz [ $\left.{ }^{\circ} \mathrm{C}\right]$.

Tabela 4. Zestawienie danych meteorologicznych za rok 2015

Table 4. Summary of meteorological data for the year 2015

\begin{tabular}{|c|c|c|c|c|c|c|c|c|c|c|}
\hline \multicolumn{10}{|c|}{ Rok 2015 } \\
\hline miesiąc & temp. & $\begin{array}{c}\text { wilgot. } \\
{[\%]}\end{array}$ & $\mathbf{p}_{\text {sat,e }}$ & $\mathbf{p}_{\mathbf{~}}$ & $\begin{array}{c}\text { delta p - } \\
\text { nadwyżka }\end{array}$ & $\mathbf{p}_{\mathbf{i}}$ & $\begin{array}{c}\mathbf{p} \text { sat }(\boldsymbol{\Theta} \\
\mathbf{i})\end{array}$ & $\boldsymbol{\Theta}_{\text {si,min }}$ & $\boldsymbol{\Theta}_{\mathbf{i}}$ & $\mathbf{f}_{\text {rsi,max }}$ \\
\hline styczeń & $-1,2$ & $71,24 \%$ & 552,33 & 393,48 & 675 & 1068,48 & 1335,60 & 11,27 & 20 & 0,59 \\
\hline luty & $-0,9$ & $63,14 \%$ & 566,26 & 357,54 & 675 & 1032,54 & 1290,67 & 10,75 & 20 & 0,56 \\
\hline marzec & 4,4 & $54,12 \%$ & 835,12 & 451,96 & 631,8 & 1083,76 & 1354,71 & 11,48 & 20 & 0,45 \\
\hline kwiecień & 6,3 & $54,02 \%$ & 953,09 & 514,86 & 554,85 & 1069,71 & 1337,13 & 11,29 & 20 & 0,36 \\
\hline maj & 12,2 & $57,51 \%$ & 1418,28 & 815,65 & 315,9 & 1131,55 & 1414,44 & 12,14 & 20 & $-0,01$ \\
\hline czerwiec & 17,1 & $56,88 \%$ & 1945,58 & 1106,65 & 117,45 & 1224,10 & 1530,12 & 13,34 & 20 & $-1,30$ \\
\hline lipiec & 19,2 & $53,93 \%$ & 2219,64 & 1197,05 & 32,4 & 1229,45 & 1536,82 & 13,40 & 20 & $-7,25$ \\
\hline sierpień & 16,6 & $58,73 \%$ & 1884,88 & 1106,99 & 137,7 & 1244,69 & 1555,86 & 13,59 & 20 & $-0,88$ \\
\hline wrzesień & 12,8 & $66,26 \%$ & 1475,23 & 977,49 & 291,6 & 1269,09 & 1586,36 & 13,89 & 20 & 0,15 \\
\hline październik & 8,2 & $72,27 \%$ & 1085,50 & 784,49 & 477,9 & 1262,39 & 1577,99 & 13,81 & 20 & 0,48 \\
\hline listopad & 2,9 & $71,21 \%$ & 751,28 & 534,99 & 692,55 & 1227,54 & 1534,42 & 13,38 & 20 & 0,61 \\
\hline grudzień & 0,8 & $69,37 \%$ & 646,41 & 448,41 & 777,6 & 1226,01 & 1532,52 & 11,66 & 20 & 0,57 \\
\hline
\end{tabular}

Maksymalna wysokość współczynnika temperaturowego wynosi 0,61. Jest to wartość obliczona dla średniomiesięcznych wartości temperatur i wilgotności w roku 2015 (tab. 4). W oparciu o parametry geometryczne warstw przekrojowych, a znaczący wpływ ma termoizolacja i jej grubość, obliczony został współ- 
czynnik temperaturowy w poszczególnych miejscach stropodachu, różniących się między sobą grubością. Wartości te wahają się między $0,976 \mathrm{w}$ miejscach $\mathrm{z}$ najgrubszą termoizolacją około $31,5 \mathrm{~cm}$ do $0,971 \mathrm{w}$ miejscach z najcieńszą termoizolacją - $25 \mathrm{~cm}$ (rys. 3).

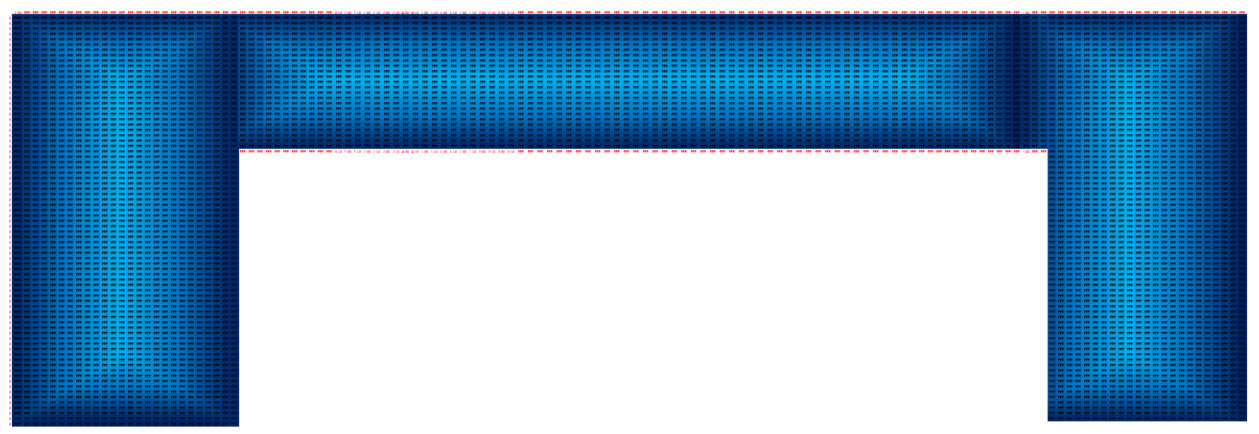

Rys. 3. Wartości współczynnika temperaturowego w każdym miejscu stropodachu - pola ciemniejsze to wartości maksymalne, pola jasne - wartości najmniejsze

Fig. 3. The values of temperature at any point of the flat roof - the darker the field the maximum values, field bright - the smallest

\section{Wnioski}

\section{Poniższy warunek:}

$$
f_{R s i}>f_{R s i, \max }
$$

został spełniony dla każdego miejsca w stropodachu. Snuje to jasny wniosek, iż w żadnym miejscu na stropodachu nie wystąpi powierzchniowa kondensacja pary wodnej, a także nie wystąpią na powierzchni wewnętrznej pleśnie i grzyby. Jest to dość ważne jeśli mamy na myśli utrzymanie właściwego mikroklimatu w pomieszczeniu mieszkalnym, zwłaszcza jeśli chodzi o osoby, które są alergikami.

\section{Literatura}

[1] Tomasz Błaszczyński i inni, Dachy - podstawy projektowania i wykonawstwa, Dolnośląskie Wydawnictwo Edukacyjne.

[2] PN-EN ISO 13788 Cieplno-wilgotnościowe właściwości komponentów budowlanych i elementów budynku - Temperatura powierzchni wewnętrznej konieczna do uniknięcia krytycznej wilgotności powierzchni i kondensacja międzywarstwowa Metody obliczania.

[3] Wojciech Dylla, Fizyka cieplna budowli w praktyce Obliczenia cieplnowilgotnościowe, PWN, Warszawa 2015. 


\section{RISK OF CONDENSATION IN THE HORIZONTAL EXTERNAL PARTITIONS}

\section{S u m m a r y}

The aim is to check the occurrence of condensation on the flat roof of green, which is covering multifamily residential building, for which specified third class load damp - buildings with low population. Flat roof has a layer system in which the variable thickness of insulation is laid with a fall in the direction of the irrigation channel. The minimum thickness of insulation is $25 \mathrm{~cm}$ and the maximum result of the calculation, is about $31.5 \mathrm{~cm}$. Determining the thickness of the insulation in the various places of the flat roof was used in increments of $50 \mathrm{~cm}$ to form a grid of points that describe the individual sections of the floor. Checks were made on the basis of the definition of the temperature coefficient. The average monthly temperature on the outside of the building was achieved based on the database of the Institute of Meteorology and Water Management for the year 2015. At the beginning of calculated monthly external pressure steam. Then they set the external pressure steam and excess internal pressure steam in a manner appropriate for the third class of moisture load. Successively calculating the internal vapor pressure and the minimum allowable vapor pressure led to calculate the minimum allowable surface temperature of the partition. For founded the layers of the roof there is a risk of condensation. This is very important not only aesthetic, but especially important for people with allergies. Avoiding all kinds of fungi and molds in the room helps to create the right microclimate.

Keywords: temperature coefficient, a green roof, condensation, temperature coefficient

Przestano do redakcji: 15.01.2017 r.

Przyjęto do druku: 31.03.2017 r. 